STIGMA, THE MORAL CAREER OF A CONCEPT: SOME NOTES ON EMOTIONS, AGENCY, TEFLON STIGMA, AND MARGINALIZING STIGMA

\author{
Thaddeus Müller ${ }^{1}$ \\ Lancaster University
}

${ }^{1}$ Direct correspondence to Thaddeus Müller, Law School, Criminology, Bowland North, C20 Lancaster University, Lancashire, LA1 4YN UK; e-mail: t.muller@lancaster.ac.uk. 


\section{STIGMA, THE MORAL CAREER OF A CONCEPT: SOME NOTES ON EMOTIONS,}

\section{AGENCY, TEFLON STIGMA, AND MARGINALIZING STIGMA}

\section{INTRODUCTION}

In July 2018, I was in the fortunate position, as the vice-president of the Society for the Study of Symbolic Interaction (SSSI) and a member of the board of the European SSSI, to organize a conference in Lancaster University (UK). This was the first annual SSSI conference outside of the USA and the first one established under the combined efforts of the European and the North American interactionist societies. The conference included one distinguished lecture and five keynote speeches: those of Kathy Charmaz, Ken Plummer and Susie Scott are published in this special issue. ${ }^{2}$ The title of the conference, "'Whose Side Are We On?' Power, Stigma, Transgression, and Exclusion in Everyday Life," combines several elements that are highly relevant in stigma studies: (1) How do we relate to the persons that we study and in what way can we contribute to the improvement of their lives? (2) Power plays a role in stigmatization; it shapes the behavior of the stigma-labeler and the person that is being labeled. Stigmatization leads to disempowerment, exclusion, marginalization, and the internalization of the stigma-label. (3) However, there is also resistance to stigma, which can empower those who are being labeled. The concept "transgression"” is used within cultural criminology: it refers to the empowering and exciting experience of resisting and fighting hegemonic societal norms in order to redefine oneself (Ferrell, Hayward, and Young 2015; Ferrell, Milovanovic, and Lyng 2001).

\footnotetext{
2 The other presentations were by Imogen Tyler, Stacey Hannem, and Staci Newmahr.

${ }^{3}$ Staci Newmahr's keynote speech, "Transgression, Intimacy, and Community: Playing Back the Edge," was on one specific form of transgression: sadomasochism.
} 
Before I introduce the articles, I will share some notes on the moral career of the stigma since the publication of Goffman's classic work.

Stigma has become part of our academic and daily vocabulary. Academic search engine Scopus shows that stigma has been used in 130,000 academic publications ${ }^{4}$ worldwide. In 2018, it was mentioned in 13,365 academic publications. LexisNexis shows that stigma has been used in over 300,000 newspaper documents in English worldwide since 1969. In 2018, over 30,000 newspaper documents in English referred to stigma. Both search engines show that there has been a massive increase of the use of stigma since the mid-2000s. It seems daunting to want to say something significant about the use of stigma in relation to these statistics. Still, I would like to share some observations on the moral career of the stigma concept by focusing on different readings of Stigma (1963b).

\section{OBSERVATION 1: THE STIGMA-PARADOX}

There is a reading of Stigma which puts an emphasis on the stigmatization of certain marginalized groups, which highlights one side of Goffman's writing. In general, authors of stigma-studies tend to refer to Stigma by focusing on the same passages and excluding those in which Goffman refers to non-marginalized groups. References to Stigma focus on the ideas that stigma is "deeply discrediting" (p. 3) and that the stigmatized person is "disqualified from full social acceptance" ("Preface") and "reduced in our minds from a whole and usual person to a tainted, discounted one" (p. 3; see also Stafford and Scott 1986).

The stigma-paradox relates to the fact that in the first three chapters of his book Goffman creates a clear, at times emotionally upsetting, unbridgeable division between those who are stigmatized and what he calls "the normals."

\footnotetext{
${ }^{4}$ Stigma also relates to an important concept in biology and related sciences. In order to create an accurate collection of stigma publications, one has to delete the non-social stigma references, which I did.
} 
We and those who do not depart negatively from the particular expectations at issue I shall call the normals. ... By definition, of course, we believe the person with a stigma is not quite human. On this assumption we exercise varieties of discrimination, through which we effectively, if often unthinkingly, reduce his life chances. We construct a stigma theory, an ideology to explain his inferiority and account for the dangers he represents, sometimes rationalizing an animosity based on other differences, such as those of social class. (Goffman 1963b:15)

However, at the end of Stigma, Goffman flips this perspective, particularly in chapter 4 "The Self and Its Other." But it seems that many authors have stopped reading Stigma before this chapter or have missed the significance of this chapter for studying stigma. Here he states that there is not an absolute difference between the stigmatized and the normals.

The most fortunate of normals is likely to have his half hidden failing, and for every little failing there is a social occasion when it will loom large, creating a shameful gap between virtual and actual social identity. (p. 127)

Goffman says that in relation to the body there are ideals in our society "against which almost everyone falls short at some stage in his life" (p. 128). Goffman supports this turn in his perspective with a reference to the fact that the multiplicity of norms "has the effect of disqualifying many persons." Goffman states in an almost sardonic way that there is one category which is free of stigma, which is interesting considering the fact that he is a Jew raised in a village in the Canadian (Mid-)West:

[T]here is only one complete unblushing male in America: a young, married, white, urban, northern, heterosexual Protestant father of college education, fully employed, of good complexion, weight and height, and a recent record in sports. (p. 128) 
It is hard to take this seriously. It almost reads like a put-on and it probably is. It is clear that most people will fall short of this ideal, which Goffman describes as "a common value system in America." Men who are not able to attain this ideal are likely to view themselves as "unworthy, incomplete and inferior" (p. 128). In the sexist language of his time, Goffman does not refer to women, but one has to assume that they fall in the same category as the men who are not able to attain this ideal.

At the end of chapter 4, Goffman says the following: "stigma involves not so much a set of concrete individuals who can be separated in two piles, the stigmatized and the normal ... [it is] a pervasive two-role social process in which every individual participates in both roles" (pp. 137-8). The implication is that there is not a vast contrast between the stigmatized and the normal. My interpretation of the first three chapters is that Goffman tricks the reader by recreating this strong contrast. He does this to show the "normals" a mirror in which they are faced with their perspective, how they treat the stigmatized. Though this "we are all in the same ship" stance might feel like a compassionate turn in his narrative, another reading is possible: a very dark representation of society. Goffman's study shows the pervasiveness of social control and how it permeates social life. ${ }^{5}$ At the end of his work, Goffman states that we can all be stigmatized, that we all have something that can discredit us, and that we all have to pass and apply tension management. This perspective is of course in line with his earlier work, especially the Presentation of Self in Everyday Life (Goffman 1959) and Behavior in Public Places (Goffman 1963a).

The logical consequence is that stigma is also experienced by those who are not marginalized, which is in contrast to the current dominant definition of stigma in sociology, which I will discuss below. His statement implies that we can speak of stigma in relation to

\footnotetext{
${ }^{5}$ Goffman wrote Stigma while he was teaching a class on "Deviance and Social Control" (Love 2014).
} 
those who have the resources to ignore it or fight it. However, the problem is that Goffman does not reflect on the consequences of this statement. Goffman fails to pay systematic attention to the latter category: how stigma works in relation to categories that can show more agency and have cultural, social, and financial resources. If we take Goffman's "we are all in the same ship" stance seriously, then we have to raise the question whether we can lump all forms of stigmas together or should we separate them and conceptualize them in different ways. In line with this reasoning, we have to ask the following questions: When does the stigma-label stick, when does it stain, and when can we speak of Teflon stigma? When is it easy for persons to let stigma go? But Goffman does not give us the answer, and because most stigma studies focus on marginalizing stigma, we don't know much about groups and persons that are able to fight stigma or about situations of Teflon-stigma. ${ }^{6}$

\section{OBSERVATION 2: NOT SO POSITIVE REVIEWS BY APOLITICAL "NORMALS"}

The reviews in the mid-sixties do not refer to the previously discussed stigma-paradox. The authors did not see it as problematic and my understanding is that they identified with the comfortable position of the normals. Goffman gets his usual praise for his keen observational qualities.

And, taking Stigma as another case in point, none see so well as Goffman.

(Weinstein 1965:636)

However, there is one thing [Stigma] does supremely well. It sharpens our perceptions. It reminds us again how complex and intricate human experience is. (Tyler 1965:32)

\footnotetext{
${ }^{6}$ There are several exceptions to this rule, such as Carrasco et al. (2017), Frank (1988), Hannem and Bruckert (2017), Kusow (2004), Schur (1980), and Thoits (2011).
} 
While reading the reviews the first thing that strikes me is that Stigma was not celebrated as a brilliant breakthrough, as for instance Outsiders of his friend Howard Becker (1963) was (Müller 2014:576). Nothing in these reviews indicates that it would become such an academic blockbuster. The author in the American Sociological Review presents a condemning portrayal of Stigma:

Despite the fact that all this is handled intelligently and gracefully, it is not very informative. Too much of the book is a collection of anecdotes about stigma troubles, and many of these anecdotes are not especially illuminating ... And although this material is interlaced with such conceptual distinctions as ... social identity and personal identity; prestige symbols and stigma symbols; cognitive and social recognition, it does not seem to me that the promise of the preface is effectively fulfilled, namely the promise of a parsimonious description within a single conceptual scheme. (Seeman 1965:770)

In the review in The American Journal of Sociology, the author is dissatisfied with Goffman's style.

In many ways, this is an irritating book. It is clearly padded, about twice as long as it needs to be. The style is tour de force-ish. There is much that is too cute and only near relevant, in sum, too much schmaltz and not enough liver. (Weinstein 1965:636)

Reading these reviews, I think it is remarkable that Stigma has become such a classic work.

\section{OBSERVATION 3: THE SUCCES OF (MARGINALIZING) STIGMA}

I believe the numerical success of Stigma has to do with the use and redefinition of stigma in relation to a specific category of persons: those who are marginalized and disempowered by a certain feature they share and that is stigmatized by society. It seems that the studies of 
certain stigmatized groups have redefined stigma into "marginalizing stigma," such as health studies and especially those focusing on HIV/AIDS and mental illness (see also Parker 2012:165). In his original and creative ethnomethodological approach, Manzo (2004) analyzed 180 titles to study the qualities that made conditions appropriate for sociologists to study them as stigma. His findings coincide with what I call "marginalizing stigma": "stigma attaches to outcomes that are almost always negative" and "stigma and power are of inverse proportions, and so stigma victimizes those identified by sociologists as relatively powerless" (p. 406). Manzo also shows that this is closely related to the dominant topic within the stigma-field of those days: 60 of the 180 studies focused on HIV/AIDS.

The transformation to marginalizing stigma is formalized in one of the most wellknown definitions of stigma (Link and Phelan 2001). ${ }^{7}$ Link and Phelan state that stigma only exists when the following interrelated components converge. The first three are labeling, stereotyping, and separation. The fourth has to do with the negative material consequences of stigma:

Labeled persons experience status loss and discrimination that lead to unequal outcomes. ... Stigmatization is entirely contingent on access to social, economic, and political power that allows the identification of differentness, the construction of stereotypes, the separation of labeled persons into distinct categories, and the full execution of disapproval, rejection, exclusion, and discrimination. (Link and Phelan 2001:367)

This definition claims one form of stigma as the "real" form of stigma. When marginalization does not take place, we cannot speak of stigma. In their own words:

\footnotetext{
${ }^{7}$ Scopus shows that over 3,200 publications refer to Link and Phelan's article and Scholar indicates even a higher number, over 7,500.
} 
Thus, we apply the term stigma when elements of labeling, stereotyping, separation, status loss, and discrimination co-occur in a power situation that allows the components of stigma to unfold. (2001:367)

Where in the 1990s HIV/AIDS dominated the stigma-field, in the last decades we have seen a vast increase in studies on stigma and mental illness. Studies on the latter group have shaped the stigma-concept in recent years. It is no coincidence that Link and Phelan are experts in mental illness, as are the authors of the more recent review on the sociology of stigma (Pescosolido and Martin 2015). Scopus shows that among the top five authors with the most publications in the stigma field in 2018, four are experts in mental illness and one in HIV/AIDS. In the overall increase of publications on (mental) health, funding by (mental) health institutes seems to play a big role. If we look at the publications funded by the top five of funding institutes, Scopus shows an increase from 55 funded publications in 2010 to 283 in 2018. If we take a closer look at two main funding organizations - the National Institute for Mental Health and the National Institutes for Health—we can see a similar increase. The first one funded 21 publications in 2010 and 81 in 2018, the latter 22 publications in 2010 and 74 in 2018 .

\section{OBSERVATION 4: A DIFFERENT AUDIENCE READING GOFFMAN}

Several decades after the first reviews, articles and books are published by authors who do not share Goffman's apolitical stance and who are on the side of stigmatized groups or in fact are (activist) members of these groups. Their scientific quest is closely linked to fighting stigma. This audience reads Stigma in a different way. They criticize Goffman because of his oversight of the role of agency, power, and structure (see also the other articles in this issue). It is true that Goffman focuses on the interaction level, but he was not naïve.

Sociologically, the central issue concerning these groups is their place in the social structure; the contingencies these persons encounter in face-to-face 
interaction is only one part of the problem, and something that cannot itself be fully understood without reference to the history, the political development, and the current policies of the group. (1963b:127; italics added)

His stance was that he did not see it as his business to look at these elements; his aim was to look at the similarities in regard to different forms of stigma. He was not interested in concentrating on one specific case of stigma and focusing on its accompanying history, political transformations, and social movements.

I have argued that stigmatized persons have enough of their situations in life in common to warrant classifying all these persons together for the purpose of analysis. (pp. 146-7)

With the redefinition of stigma into marginalizing stigma, we see also an increase in "new" terms and approaches that should help us understand how society constructs marginalizing stigma. It is impossible to name or let alone discuss all these terms. I present here a small selection. Link and Phelan (2014:24) coined the concept stigma power which refers to "instances in which stigma processes achieve the aims of stigmatizers with respect to the exploitation, management, control or exclusion of others." Hannem's conference keynote speech "Risk, Structural Stigma, and the Exercise of Power" combines a symbolic interactionist perspective with a critical and structural approach to stigma.

Hannem (who studied families of male prisoners) makes a distinction between "symbolic and individualized stigma" and "structural stigma." The latter "arises out of an awareness of the problematic attributes of a particular group of people and is based on an intent to manage a population that is perceived, on the basis of the stigmatic attribute, to be ‘risky’ or morally bereft” (Hannem 2012:24). Hannem suggests combining the Goffmanian micro perspective with a historical approach inspired by Foucault to understand the relation between power, knowledge, and stigma. Imogen Tyler, who gave a conference keynote 
presentation on rereading Goffman through the lens of Black Sociology, speaks in her forthcoming book, Stigma: The Machinery of Inequality, of "stigma machines." These are the devices of stigma construction through which groups are stigmatized in order to sustain the accumulation of power and finance within an elite that profits from the current neoliberal climate (Tyler 2020). ${ }^{8}$

In addition to providing an overview of critical readings of Goffman, Tyler's work is also relevant because of her radical analysis of Stigma and Goffman. While many criticize his approach because of his apolitical detached stance, she goes one step further. Her reading is informed by the intention to decolonise Goffman's work by placing Stigma in the historical context of the anti-stigma struggles of the 1960s Civil Rights Movements. In her writing, one can feel her rage against the stigma machine. Tyler describes how Goffman's Stigma is part of this machine. Stigma is in her analysis a conservative and conformist account, which maintains public order and solidifies the marginalized positions of stigmatized groups (Tyler and Slater 2018; Tyler 2018, 2020).

Disability studies has a long tradition of rigorous and inspiring critique of Stigma, that focuses on a range of issues such as agency, activism, structure, power, and emotions (Brune 2014; Fine and Asch 1988; Frank 1988; Garland-Thomson 2014; Gleeson 1999; Love 2014). Green (2016) describes in a brilliant publication Managing the Emotions of Reading Goffman, how she and her students experience reading Stigma. Green (2016:45) "bristled at the othering tone of Goffman" and feels his prose is "vulgar and insulting." However, she also adds that "reading Stigma is like crossing a minefield to get a great prize" (p. 46). This great prize is a deeper and often painful understanding of the interactional process of

\footnotetext{
${ }^{8}$ Goffman was already criticized for neglecting power and structure in his work since the early seventies. For a detailed discussion of this topic, see Smith and Hviid Jacobsen (2019).
} 
stigmatization. Green quotes a long passage of one of her former students to show how they read Goffman and came to a deeper appreciation.

In my initial reading, I did not like the work. Emotionally, I rejected and refused to identify with stigma as Goffman presented it. I sensed a degree of judgmental aloofness from Goffman, and I did not think that he had anything to tell me about my own feelings about my hearing impairment. I thought that Goffman's perspective was an outsider's view, one that judged how stigmatized people should feel. I was not willing to accept or identify with this. It was only later, as I went through the process of writing my thesis and began exploring my own experiences with stigma, that I was better able to understand, appreciate, and value Goffman's keen sociological eye for interpreting social interactions. (Perry 1996:231, cited in Green 2016:48)

A similar reaction can be found in the publications of the panelists of the forum on "Reflections of the Fiftieth Anniversary of Stigma" at the annual meetings of the Society for Disability Studies 2013. I deeply enjoyed reading these powerful and moving essays. Each of them is highly critical and constructive in their reading of Goffman. Garland-Thomson describes her rereading of Stigma as "unsettling" and for her it was like "witnessing roadkill: the shock of seeing a thing familiar and unremarkable splayed open in a disarray, exposing a reeking but somehow affirming truth about life.” Love highlights her reaction to Goffman's emotionally, chilling stance:

In addition to his use of a flattening language, several other features of Goffman's work make him a troubling figure today: his lack of a positive account of difference; his attitude of detachment, even or especially when he is writing about situations of human degradation. (Love 2014) 
Almost all these authors end their critical essay on Stigma with a statement referring to what Goffman did contribute to their understanding of stigma. For instance, Love ends her essay by referring to a citation, which is related to his "we are all in the same ship" statement at the end of Stigma:

Although Goffman's blunt language, rough editorial cuts, and micro-scale analyses are often out of step with the protocols of the contemporary field of disability studies, it was these aspects of his method that led him to conclude that "the normal and the stigmatized are not persons but rather perspectives." (Love 2014:138)

\section{OBSERVATION 5: A CLOSER LOOK AT THE STATISTICS: THE}

\section{MARGINALIZATION OF GOFFMAN'S STIGMA}

Most studies that criticize or reject Stigma represent Goffman as having a crucial position in the stigma-field. His work is seen as a hallmark and as classic and pioneering. There also tends to be a reference to numbers that indicate the importance of his work. For instance, Tyler (2018:747) refers to the fact that Stigma has sold 800,000 copies and therefore had considerable influence.

In many publications, Goffman functions as a straw man in order to position one's work. Stigma is transformed into a stereotype by emphasizing certain elements and leaving out others. Of course, Goffman's choice of phrasing and composing his book-his stigmaparadox — can understandably lead to a unidimensional decontextualized reading of Stigma. However, in many publications Stigma is used to situate one's research and emphasizes one's contribution to science. Parker, who together with Aggleton published pioneering work on HIV/AIDS and stigma, has admitted using Goffman in this way. 
It should be noted that, in fairness to Goffman, who we probably used as something of a straw man in order to construct our argument, his original model actually placed greater emphasis on process than we gave him credit for. (Parker 2012:166)

After 40 years of criticism, I wonder how relevant Goffman's Stigma is for the stigma-field? Does he still have a considerable influence? One way of answering this question is to look at references to this work. Search engine Scopus counts 12,022 documents that refer to Stigma until 2018. There has been a slow increase in the first decades. In 1990, 59 publications referred to Stigma. In 2010, this was 441 publications and 960 in 2018. Almost all 12,022 publications were published since $2000(96 \%)$ and two thirds were published in the period 2010 to 2018 (63\%). However, in order to see the relevance of Goffman for publications on stigma one has to focus on a wider category of publications. I have chosen to look at publications that have stigma in the title, abstract, and/or keywords and also have a reference in the literature to a title which has stigma in it. I will call these the stigma publications. With these publications, we again see an increase in the last decade. Almost half of these documents were published in the period 2015-2018 and close to 80\% from 2010.

In my analysis of this data, I calculated the percentage of the stigma publications which refer to Goffman. During the 1990s this percentage varied between $48 \%$ and $33 \%$. In the 2000s we can see a decrease: most scores were between $35 \%$ and $25 \%$. From 2010 the steady decrease continues, from $25 \%$ to $19 \%$ in 2018. It is clear that Goffman's Stigma is becoming marginalized over time. The numbers for 2019 indicate that this trend continues: $18 \%$. In order to understand this change, I started to have a closer look at stigma publications and see how stigma is defined and which references are used. This is still a work in progress 
but based on an analysis of a sampled subset of 50 publications ${ }^{9}$ I can share some preliminary findings. Of these publications 29 were health related, and of these HIV/AIDS and mental health formed two thirds. The other publications consisted of a variety of topics, such as sex work, race, and LGBTQ+. Only in a limited number of publications is there a reference to Goffman's Stigma. Of the 29 health-publications only 4 referred to Goffman's Stigma (14\%), out of the other 21 other publications $7 \mathrm{did}(33 \%)$. In almost all these publications, we see a similar depiction as Manzo (2004) observed. These articles tend to reproduce the image of "marginalizing stigma": the stigmatized have hardly any power or agency to resists or fight stigma.

I have been able to categorize three general interlinked explanations. (1) There is no reference to any other publication on stigma in publications in which stigma is mentioned less than 20 times. My understanding is that stigma is not seen as a core category which needs a definition or reference to Goffman, Link and Phelan, or any other academic. (2) This explanation sometimes overlaps with the first one: the meaning of stigma is taken for granted and does not need to be defined with the help of a reference to Goffman's Stigma or any other publication (see also Stafford and Scott 1986). In relation to explanation 1 and 2, I would like to add that it seems that because stigma has become part of our daily vocabulary, authors assume that the reader understands what they mean by stigma. Sometimes the use of stigma becomes clear because of how it is used in an article. In the following examples stigma equals embarrassment. The first one is from an article on getting professional help for mental illness in China.

\footnotetext{
${ }^{9}$ I have sampled every seventh publication of a sample over 700 stigma publication from 2018 which I retrieved with Scopus and fall under their category of Social Sciences.
} 
Related to the issue of confidentiality is the embarrassment or stigma that is a major cultural barrier to professional help-seeking. (Chen 2018:766; italics added)

The second example comes from an article on dyslexia among medicine students:

Participants conveyed fear of disclosure (of dyslexia, TM) and stigma — as a result of others' responses towards them-during the interviews. [For example,] "I just feel embarrassed. I feel embarrassed because I struggle." (Shaw and Anderson 2018:8; italics added)

(3) Stigma has become part of a specific discipline and has been redefined in its publications. The article is published in a journal for a specific audience who refers to a specific subset of stigma publications and therefor does not need to refer to Goffman anymore. "HIV stigma" is an example of a concept which has become part of the standardized conceptual framework in studies on HIV/AIDS and stigma. HIV stigma is a common term in HIV/AIDS studies. Stigma has been a topic in publications on HIV/AIDS since the late 1980s. Another example is self-stigma (internalized sigma) developed by Corrigan (2004). ${ }^{10}$ There is a sub discipline in stigma studies and mental health that focuses on self-stigma. There is no need to refer to Goffman because authors can refer to many publications in this sub-discipline.

\section{OBSERVATION 6: STIGMA BEYOND ACADEMIA: STIGMA SOCIETY}

In the last half century, thousands of publications have described and analyzed how stigma works for many different marginalized categories in society. One conclusion is that many people will have a self that is being stigmatized. The term stigma society covers this wide spectrum of discredited persons, which includes the marginalized stigmatized groups,

\footnotetext{
${ }^{10}$ Corrigan is a psychologist and many of his publications are actually on resisting stigma (see also The National Consortium on Stigma and Empowerment, http://www.stigmaandempowerment.org/).
} 
frequently studied by sociologists, and not so marginalized groups, which are hardly studied within the social sciences.

The generalness of stigma is shown by its common use in our daily vocabulary. For instance, LexisNexis shows that in 2018 close to 30,000 newspaper articles in English referred to stigma. The crucial question is of course: how is stigma used and to what does it refer to. In her keynote speech, Hannem indicates that stigma is loosely used nowadays in academic and popular media. She states that there is a broader cloudy usage of stigma. She rejects that stigma is being used to describe a personal emotional experience without any reference to power or structure. I fully agree with her, but at the same time, I am also interested in this broader use of stigma and what it says about our society. This blurred use of stigma seems in itself a valuable object for sociological research.

To explore how stigma is used and how it acquires meaning, I have looked at the first half year of the New York Times in 2018. I analyzed every second article that had a reference to stigma - in total, 112 documents. ${ }^{11}$ Most of the publications used stigma in relation to the traditional marginalized and stigmatized groups. Mental health had the highest score (20), followed by LGBT+ (8), HIV/AIDS (6), and drugs (6). There is also a usage of stigma that is related to situations of rejection that do not seem related to marginalization, such as not supporting Sexual Offense Prevention Policy and booking online.

In the summer of 2017 , a student group organized a concert featuring several local bands, that would take place at the on-campus amphitheater. Nonstudents from beyond Yellow Springs attended. They were asked to sign the document stating that they understood and would respect the S.O.P.P. (Sexual Offense Prevention Policy). Several of the men refused to sign; they were approached

\footnotetext{
${ }^{11}$ In the first six months, there were 275 hits on stigma, but these also contain doubles: the same article appears twice. When I encountered a double, I would skip this publication and analyze the next one.
} 
by students who asked them to sign the document or to leave. They left.

"There is a stigma to not signing," Ms. Berro said. (Rosman 2018)

For example, Mr. Kelly said that some hotels offer best price guarantees, so if you find a cheaper price than the one the hotel advertises on their own website, they will match it. More properties are willing to do this, Mr. Barba said, so it can't hurt to call and at least ask. "At other hotels, I've seen a stigma associated with guests that booked with an online agency," he added. "They don't get the same attention and may even get assigned to their 'last sell' room types." As you can imagine, these are less desirable rooms, usually smaller, near an elevator or without a view. (Wong 2018)

Stigma, in these two examples, does not seem related to the traditional stigmatized groups that sociologists study. In total, there are 16 references (14\%) to stigma that are not in line with the current dominant definition within sociology. However, when we only focus on marginalized groups, we will not be able to describe and analyze these other social meanings of stigma. Including non-marginalized groups does not mean that we overlook the relevance of power, agency, and structure as Link and Phelan (2001:376) have stated, rejecting a broader definition of stigma:

The definition of stigma must involve reference to power differences. Without such a reference, stigma becomes a very different and much broader concept that might be applied to lawyers, politicians, Wall Street investors, and white people. Stigma is dependent on power.

I think that beside our focus on marginalizing stigma there should be space for researching the stigma experience of groups that are not part of the traditional stigmatized categories, as well as claims about these experiences. Studying this form of stigma can shed some light on 
the changing social world we live in. Has stigma become a common experience among new groups because of the dominance of hyper individual neoliberalism? Lamont states that neoliberal narratives have widened what she calls the "recognition gap," which she defines as "disparities in worth and cultural membership between groups in a society" (Lamont 2018:421-22). She relates this to traditional stigmatized groups, but also to the working class and to Trump supporters. The broader use of stigma can be an indication that new groups are confronted with situations in which they are "disqualified from full social acceptance" (Goffman 1963b:9), which makes them feel like second class citizens.

Our general understanding of the social construction of stigma and its meanings for persons involved in the stigma-process will improve when researchers study stigma beyond marginalizing stigma and return to Goffman's broad definition of stigma with the enhanced awareness of agency, power, and structure. This means that researchers focus on those within traditional stigmatized groups who do resist and fight stigma and that researchers also have an eye for those who do not belong to these groups. The symbolic interactionist tradition has developed an approach with which researchers can describe and analyze the stigma process in detail and how it leads to different meanings and reactions. Why do Ms. Berro and Mr. Barba use stigma and what does it mean to them? How does this shape their daily live (see Aliraza Javaid's article in this issue)? How do people manage the stigma of booking online? And for which category is this relevant anyhow? Does the stigma-label of not supporting S.O.P. P. stick or stain? Or can we speak of Teflon-stigma: is it easy for the men who refused to sign to let it go and does this hardly shape their lives (see Eric Silva and Matthew Flynn's article in this issue)? Moreover, if this is not the case, what kind of resources do they use to manage or even fight stigma (see Avihu Shoshana's article in this issue)? In what way does power and structure shape their agency? To understand the social construction of the stigma process we also have to go beyond the immediate interaction and its meanings and see how they are 
related to societal narratives that dominate, exploit but also liberate (see Kathy Charmaz's and Ken Plummer's articles in this issue). Classic studies in the symbolic interactionist tradition have showed how moral entrepreneurs create stigmatizing narratives and these can be used as inspirational examples to study how these narratives are developed and used to control marginalized groups in society (e.g., Becker 1963; Douglas 1970; Erikson 1966; Gusfield 1963; Schur 1980).

Looking at cases beyond marginalizing stigma and using Goffman's broad definition of stigma might help us to understand the workings of stigma from a different angle. In sum, with the knowledge gained studying the stigma of different groups we can start comparing these stigmas, which will help us understand the complexities of the social production of stigma and how different groups react to it. I would like to end my observations with the last sentence of Stigma:

The development of ... coherent analytic perspectives is not likely to come from those who restrict their interest exclusively to one substantive area. (Goffman 1963b:147)

\section{FINAL OBSERVATION: OVERVIEW OF THE SPECIAL ISSUE}

The contributors in this special issue all connect with the questions and themes I discussed above in different ways, using a variety of methods and focusing on different dimensions of the stigma process. Most of them share (1) a thick description of how the meanings of stigma are socially constructed in daily interactions and (2) how this is also shaped by stigmatizing narratives and counter narratives. In these articles, many of the themes I discussed above, such as activism, power, agency, and emotions, play a crucial role in the understanding of stigma. The first contribution is Kathy Charmaz's “Experiencing Stigma and Exclusion: The 
Influence of Neoliberal Perspectives, Practices, and Policies on Living with Chronic Illness and Disability." This inspiring article is based on her distinguished lecture for the conference. It is related to the micro-macro debate in relation to Goffman's Stigma and how societal forces shape the social construction of stigma. Charmaz relates micro sociological observations (published and unpublished) from her 50-year career to macro sociological economic and political forces within neoliberalism. She shows that the characteristics of neoliberalism, such as hyper individualism and a decrease of the welfare system, have created a situation of further exclusion and marginalization of chronically ill and disabled people. She describes how in this hyper competitive culture chronically ill and disabled people are faced with stigma in private and public situations, such as when receiving a diagnosis, disclosing illness, and dealing with disabilities and unpredictable bodies.

The second contribution comes from another keynote speaker, Ken Plummer. In his commanding contribution “'Whose Side Are We On?’ Revisited: Narrative Power, Narrative Inequality, and a Politics of Narrative Humanity," he starts with reflections on the current relevance of Becker's Presidential address at the American Society for the Study of Social Problems published in 1967. Inspired by a range of critical and activist voices that have been fighting stigma and claiming their rightful societal position since the late sixties, Plummer develops a generic theory of narrative power, which has at its core symbolic interaction. His article focuses on the mechanisms of both narratives of power and the power of narratives. Plummer discusses narrative power in relation to domination, exclusion, negotiation, and resistance. In the end, Ken Plummer reflects on his answer to Becker's question: on the side of humanity. Though humanity is a contested notion, Plummer says it forces us to seek our complex, changing, and perpetually negotiable common ground. This means that we have to be engaged in narratives of compassion that include "others." From this, as Ken Plummer states, political action can flow, and a politics of humanity can be cultivated. 
In the third article, Aliraza Javaid shows how personal micro sociological narratives can help us understand how stigma creates invisibility, silence, and desolation in daily life. His moving and challenging article, "The Haunting of Shame: Autoethnography and the Multivalent Stigma of Being Queer, Muslim, and Single," uses scenes from his own life to reflect on the multi-layered situational meanings of stigma. Javaid shows how his participation in family meetings transforms him into the stigmatized other. He is confronted with the rejection of his single identity and with expectations of his family that he has to get married or face the consequences: he will not be embraced as a fully accepted member of his family. Javaid also analyzes his position in the gay community in which he participates. In this world, he is labeled with the stigma of being a Muslim single with a brown skin, which also transforms him into an outsider. With this article, Javaid applied autoethnography to explore a new terrain in the stigma field, focusing on how the attributes of being queer, Muslim, and single were used to spoil his identity in two different communities. At the same time, this article also shows his resilience and resistance to stigmatization.

Avihu Shoshana's article, "Love, Stigma, and Resistance: "Therapeutic Microaggressions" in a Prisoners' Wives' Support Group" examines therapeutic and dynamic interactions between clinical social workers and prisoners' wives in Israel. This article shows with great ethnographic data the dramatic conflict these women have with the social workers over the definition of love. The latter group wants the prisoners' wives to accept an individualistic therapeutic definition of love that focuses on self-development, while the wives stick to a collectivist definition that centers on commitment and compassion. The women resist the social workers' definition out of awareness of their stigmatization related to ethnic hierarchies in Israel. Though the prisoners' wives gain social benefits by embracing the therapy in the support group, they were not silenced and showed agency by collectively 
resisting "therapeutic microaggressions." This article shows how stigma is shaped by power, structure, and agency, which includes the breathtaking resistance of the prisoners' wives.

The next paper in this issue is Eric O. Silva's and Matthew B. Flynn's "Liminal Stigma and Disaligning Activity: Online Comments about Trump's Family Separation Policy." Similar to Shoshana's work, this study is about actors resisting labels and stereotypes. Based on an analysis of 1,500 comments, Silva and Flynn describe the online stigma contest (Schur 1980) between separation challengers and separation advocates. Both groups react to videos covering the imprisonment of children separated from their parents. The authors develop an inspiring and challenging concept that captures the processual nature of stigma when both parties do not accept the authority and power of the other: "liminal stigma." They use their data on abusive and vicious comments, and the literature on stigma and (dis-)aligning, to push the field forward. Liminal stigma relates to interactions in which the self is discredited, while it does not automatically result in status degradation, discrimination, and exclusion.

The final article adheres more loosely to the conference theme, though close reading does show a relation with stigma. Still, I am very happy to include Susie Scott's thoughtprovoking article, based on her keynote presentation "The Unlived Life Is Worth Examining: Nothings and Nobodies behind the Scenes." Her publication is on the sociology of lives that did not take place as she explores narratives of unlived non-experiences and their meanings. Scott has developed a symbolic interactionist theory of negative social phenomena and uses this to describe and analyze 27 personal narratives on nothings and nobodies. One example is about people with mental illness. A participant writes that because of the lack of supporting services, they sense they are not seen or heard, and feel like they do not exist. These stories cover a range of experiences, from sadness and stigma, to acceptance and gratitude. This 
wonderful article reveals our ever-present shadow lives and shows the complexity of how we try to make sense of ourselves and the world we live in.

\section{CONCLUSION}

In this essay, I have taken a symbolic interactionist stance towards Goffman's Stigma and focused on the meanings of this classic study for different audiences. Though Goffman developed a broad definition of stigma, applicable to many people, the dominant reading of his classis work, shaped by health studies, resulted in a specific reading and usage: marginalizing stigma. Studies that adhere to this definition focus on how stigma plays a crucial role in the marginalization of specific groups. This in itself is needed and justified because of the severe negative consequences of stigma. However, at the same time this perspective tends to reduce the stigma process to a static situation in which powerless persons face stigma that marginalizes them. A broader definition, inspired by Goffman, and supported by the advances in the stigma field in the last decades, such as the emphasis on power, agency, and structure, can lead researchers to describe and analyze the daily complexities of the stigma process in rich detail and how this is shaped by biographies, narratives, and actions. This approach will also pay attention to the voices of resistance and study individual and collective strategies to resist and overcome stigma. I hope that with the findings of these cases we can support others in their fight against stigma.

\section{ACKNOWLEDGMENTS}

I thank the authors for participating in the conference and in the special issue. It was inspirational to work with them and I hope readers enjoy the results of their efforts. I want to thank editor Scott Harris for his supportive and collegial teamwork. Because Kathy Charmaz was physically unable to do the editing for the last draft of her paper, Adele Clarke and Scott Harris both stepped in and helped finish her contribution to this special issue. Finally, I would 
like to thank Michael Dellwing and Greg Smith for the inspiring discussion we had on Goffman's Stigma in Pisa in Spring 2019.

\section{REFERENCES}

Brune, Jeffrey. 2014. “Reflections on the Fiftieth Anniversary of Erving Goffman's Stigma: In Defense of Stigma, or at Least Its Adaptions.” Disability Studies Quarterly 34(1).

Carrasco, Maria Augusta, Clare Barrington, Caitlin Kennedy, Martha Perez, Yeycy Donastorg, and Deanna Kerrigan. 2017. “'We Talk, We Do Not Have Shame’: Addressing Stigma by Reconstructing Identity through Enhancing Social Cohesion among Female Sex Workers Living with HIV in the Dominican Republic.” Culture, Health \& Sexuality 19(5):543-556.

Chen, Juan. 2018. "Some People May Need It, but Not Me, Not Now: Seeking Professional Help for Mental Health Problems in Urban China." Transcultural Psychiatry $55(6): 754-774$.

Corrigan, P. 2004. "How Stigma Interferes with Mental Health Care.” American Psychologist 59(7):614-625.

Douglas, Jack D. 1971. American Social Order: Social Rules in a Pluralistic Society. New York: Free Press.

Erikson, Kai. 1966. Wayward Puritans: A Study in the Sociology of Deviance. New York: John Wiley.

Ferrell, Jeff, Keith Hayward, and Jock Young. 2015. Cultural Criminology: An Invitation. London: Sage.

Ferrell, Jeff, Dragan Milovanovic, and Stephen Lyng. 2001. "Edgework, Media Practices, and the Elongation of Meaning: A Theoretical Ethnography of the Bridge Day Event." Theoretical Criminology 5(2):177-202. 
Fine, Michelle, and Adrienne Asch. 1988. "Disability beyond Stigma: Social Interaction, Discrimination, and Activism.” Journal of Social Issues 44(1):3-21.

Frank, Gelya. 1988. "Beyond Stigma: Visibility and Self-Empowerment of Persons with Congenital Limb Deficiencies.” Journal of Social Issues 44(1):95-115.

Garland-Thomson, Rosemarie. 2014. "Reflections on the Fiftieth Anniversary of Erving Goffman's Stigma: Roadkill Truths.” Disability Studies Quarterly 34(1).

Gleeson, Brendan. 1999. Geographies of Disability. London: Routledge.

Goffman, Erving. 1959. The Presentation of Self in Everyday Life. Garden City, NY:Doubleday Anchor Books.

Goffman, Erving. 1963a. Behavior in Public Places: Notes on the Social Organization of Gatherings. New York: The Free Press.

Goffman, Erving. 1963b. Stigma: Notes on the Management of Spoiled Identity. Englewood Cliffs. NJ: Prentince-Hall Inc.

Green, Sara E. 2016. "Managing the Emotions of Reading Goffman: Erving Goffman and Spencer Cahill Looking at Disability." Pp. 39-56 in Sociology Looking at Disability: What Did We Know and When Did We Know It. Bingley, UK: Emerald.

Gusfield, Joseph R. 1963. Symbolic Crusade: Status Politics and the American Temperance Movement. Urbana, Chicago: University of Illinois Press.

Hannem, Stacey. 2012. "Theorizing Stigma and the Politics of Resistance: Symbolic and Structural Stigma in Everyday Life.” Pp. 10-28 in Stigma Revisited: Implications of the Mark, edited by Stacey Hannem and Chris Bruckert. Ottawa: University of Ottawa Press.

Hannem, Stacey, and Chris Bruckert. 2017. “'I'm Not a Pimp, but I Play One on TV': The Moral Career and Identity Negotiations of Third Parties in the Sex Industry." Deviant Behavior 38(7):824-836. 
Kusow, A. M. 2004. “Contesting Stigma: On Goffman's Assumptions of Normative Order.” Symbolic Interaction 27(2):179-197.

Lamont, Michele. 2018. “Addressing Recognition Gaps: Destigmatization and the Reduction of Inequality." American Sociological Review 83(3):419-444.

Link, Bruce G., and Jo C. Phelan. 2001. "Conceptualizing Stigma.” Annual Review of Sociology 27(1):363-385.

Link, Bruce G., and Jo Phelan. 2014. “Stigma Power.” Social Science \& Medicine 103:2432.

Love, Heather. 2014. "Reflections on the Fiftieth Anniversary of Erving Goffman's Stigma: Missing Persons.” Disability Studies Quarterly 34(1):\#\#.

Manzo, John F. 2004. “On the Sociology and Social Organization of Stigma: Some Ethnomethodological Insights.” Human Studies 27(4):401--416.

Müller, Thaddeus. 2014. "Chicago, Jazz, and Marijuana: Howard Becker on Outsiders.” Symbolic Interaction 37(4):576-594.

Parker, Richard. 2012. "Stigma, Prejudice and Discrimination in Global Public Health." Cadernos de Saúde Pública 28:164-169.

Pescosolido, Bernice A., and Jack K. Martin. 2015. "The Stigma Complex.” Annual Review of Sociology 41:87-116.

Rosman, Katherine. 2018. “The Reinvention of Consent.” New York Times, February 24. Retrieved October 9, 2019 (https://www.nytimes.com/2018/02/24/style/antiochcollege-sexual-offense-prevention-policy.html).

Schur, Edwin M. 1980. The Politics of Deviance: Stigma Contests and the Uses of Power. Englewood Cliffs, NJ: Prentice-Hall.

Seeman, Melvin. 1965. "Reviewed Work: Stigma: Notes on the Management of Spoiled Identity by Erving Goffman.” American Sociological Review 29(5):770-71. 
Shaw, Sebastian C. K., and John L. Anderson. 2018. "The Experiences of Medical Students with Dyslexia: An Interpretive Phenomenological Study.” Dyslexia 24(3):220-233.

Smith, Greg Jacobsen and Michael Hviid Jacobsen. 2019. "Misgivings about Goffman: Social Structure, Power and Politics in the Work of Erving Goffman.” Pp. 12-29 in Critical and Cultural Interactionism: Insights From Sociology and Criminology, edited by Michael Hviid Jacobsen. London: Routledge.

Stafford, Mark C., and Richard R. Scott. 1986. “Stigma, Deviance, and Social Control.” Pp. 77-91 in The Dilemma of Difference, edited by Stephen C. Ainlay, Gaylene Becker, and Lerita M. Coleman. Boston, MA: Springer.

Thoits, Peggy A. 2011. "Resisting the Stigma of Mental Illness.” Social Psychology Quarterly 74(1):6-28.

Tyler, Leona. 1965. "Book Review: Stigma: Notes on the Management of Spoiled Identityby Erving Goffman.” Contemporary Psychology: A Journal of Reviews 10(1):30-32. Tyler, Imogen. 2018. "Resituating Erving Goffman: From Stigma Power to Black Power.” The Sociological Review 66(4):744-765.

Tyler, Imogen Elizabeth. 2020. Stigma: The Machinery of Inequality. London: Zed Books. Tyler, Imogen, and Tom Slater. 2018. "Rethinking the Sociology of Stigma." The Sociological Review Monographs 66(4):721-743.

Weinstein, Eugene. 1965. "Book Review: Stigma: Notes on the Management of Spoiled Identity by Erving Goffman.” American Journal of Sociology 70(5):636.

Wong, Kristin. June 27, 2018 Wednesday 12:07 EST 11 Ways to Save Money When Booking Travel The New York Times Retrieved October 9, 2019 (https://www.nytimes.com/2018/06/27/travel/ways-to-save-money-when-bookingtravel.html). 
Thaddeus Müller is a senior lecturer at the Law School of Lancaster University (criminology). He has researched a range of topics within the symbolic interactionist fields of culture, crime, and transgression, such as the criminalization and normalization of drugs, the social construction of safety in public spaces, and defaulting homeowners facing stigma and fighting Wall Street. Within these themes, he focuses on the effects of stigma/labeling and resisting stigma/labeling (and its effects) through the (collective) construction of empowering (counter-)narratives. He has published in a wide range of journals, such as Symbolic Interaction, Qualitative Sociology Review, Critical Criminology, and The British Journal of Criminology. 